\title{
O marketing de conteúdo como ferramenta de divulgação científica das inovações do concreto
}

\author{
Content marketing as a tool to disseminate concrete innovations
}

El marketing de contenidos como herramienta de difusión de innovaciones concretas

Thamara Serafim Arcanjo

ORCID: https://orcid.org/0000-0003-3831-8033 Universidade Federal dos Vales do Jequitinhonha e Mucuri, Brasil E-mail: thamara.arcanjo@ufvjm.edu.br

Karine de Oliveira Santos ORCID: https://orcid.org/0000-0003-0005-5688 Universidade Federal dos Vales do Jequitinhonha e Mucuri, Brasil E-mail: karine.oliveira@ufvjm.edu.br

Pedro Henrique Amaral Lima ORCID: https://orcid.org/0000-0001-8101-1956 Universidade Federal dos Vales do Jequitinhonha e Mucuri, Brasil E-mail: pedro.amaral@ufvjm.edu.br

Marcio Coutinho de Souza ORCID: https://orcid.org/0000-0002-4238-1572 Universidade Federal dos Vales do Jequitinhonha e Mucuri, Brasil E-mail: marcio.souza@ufvjm.edu.br

Antônio Jorge de Lima Gomes ORCID: https://orcid.org/0000-0001-9560-6213 Universidade Federal dos Vales do Jequitinhonha e Mucuri, Brasil E-mail: antonio.gomes@ufvjm.edu.br

Stênio Cavalier Cabral

ORCID: https://orcid.org/ 0000-0001-5241-9776 Universidade Federal dos Vales do Jequitinhonha e Mucuri, Brasil E-mail: stenio.cavalier@ufvjm.edu.br Mauro Lúcio Franco ORCID: https://orcid.org/0000-0003-2114-4399 Universidade Federal dos Vales do Jequitinhonha e Mucuri, Brasil E-mail: mlfranco@ufvjm.edu.br

Raquel de Souza Pompermayer ORCID: https://orcid.org/0000-0002-2455-3027 Universidade Federal dos Vales do Jequitinhonha e Mucuri, Brasil E-mail: raquel.pomper@ufvjm.edu.br

Ivana Carneiro Almeida ORCID: https://orcid.org/0000-0001-6069-919X Universidade Federal dos Vales do Jequitinhonha e Mucuri, Brasil E-mail: ivana.carneiro@ufvjm.edu.br

Catarina Ferreira da Conceição Rodrigues da Silva ORCID: https://orcid.org/0000-0001-5995-2522

Universidade Federal dos Vales do Jequitinhonha e Mucuri, Brasil E-mail: catarina.silva@ufvjm.edu.br

\begin{abstract}
Resumo
O Brasil tem expandido seus meios de divulgação científica, sendo transformado pela era digital que se constrói numa variedade de âmbitos sociais. A elaboração de conteúdos, bem como a sua disseminação em plataformas digitais tornou-se uma estratégia eficiente para profissionais de diversos setores. Estudos científicos têm voltado constantemente para o desenvolvimento de novas tecnologias, abrangendo o concreto e desencadeando múltiplas possibilidades para sua aplicação. Nesse contexto, o presente artigo objetiva demonstrar que a divulgação científica relacionada às inovações do concreto pode ser desenvolvida por meio do marketing de conteúdo. A partir de um enfoque qualitativo, realizou-se um levantamento bibliográfico para embasamento teórico e análise crítica, bem como a utilização de métodos quantitativos para obtenção de dados gerais por meio do programa Not Just Analytics. Tendo como parâmetro as métricas de engajamento do Instagram do projeto Construção + , foram selecionados 4 posts que viabilizaram a análise das interações públicas. Como resultado das análises realizadas, verificou-se que a taxa de engajamento do perfil foi de 4,27 \%; a média de curtidas por publicação atingiu 30 e a média de comentários 6; a frequência dos posts foi de 4,17 dias. Por fim, são apresentadas as hashtags mais utilizadas nas publicações. Portanto,
\end{abstract}


constata-se que o projeto utiliza, claramente, o marketing de conteúdo como uma ferramenta para criar relacionamentos duradouros e levar conhecimento científico, mais especificamente, relacionado à construção civil, proporcionando aos seus usuários uma linguagem clara e de fácil compreensão.

Palavras-chave: Divulgação científica; Marketing de conteúdo; Concreto; Instagram.

\begin{abstract}
Brazil has expanded its means of scientific dissemination and is being transformed by the digital age that is being built in a variety of social spheres. The development of content and its dissemination on digital platforms has become an efficient strategy for professionals from different sectors. Scientific studies have constantly focused on the development of new technologies covering concrete, triggering multiple possibilities for its application. In this context, this article aims to demonstrate that scientific dissemination related to concrete innovations can be developed through content marketing. From a qualitative approach, a bibliographical survey was carried out for theoretical basis, as well as a critical analysis, in addition to quantitative methods for obtaining general data through the Not Just Analytics program. Based on Instagram's engagement metrics for the Construction + project, 4 posts were selected that enabled the analysis of public interactions. As a result of the performed analyses, it was found that the profile engagement rate was in the order of $4.27 \%$; the average of likes per publication was equal to 30 and the average of comments equal to 6; the frequency of posts was 4.17 days; and, finally, the most used hashtags in publications are presented. Therefore, it appears that the project clearly uses content marketing as a tool to create lasting relationships and bring scientific knowledge, more specifically related to civil construction, providing its users with a clear and easy-to-understand language.
\end{abstract}

Keywords: Scientific divulgation; Content marketing; Concrete; Instagram.

\title{
Resumen
}

Brasil ha ampliado sus medios de difusión científica y está siendo transformado por la era digital que se construye en diversas esferas sociales. El desarrollo de contenidos y su difusión en plataformas digitales se ha convertido en una estrategia eficaz para profesionales de diferentes sectores. Los estudios científicos se han centrado constantemente en el desarrollo de nuevas tecnologías que cubren el hormigón, generando múltiples posibilidades para su aplicación. En este contexto, este artículo tiene como objetivo demostrar que la difusión científica relacionada con innovaciones concretas se puede desarrollar a través del marketing de contenidos. Desde un enfoque cualitativo, se realizó un levantamiento bibliográfico con base teórica, así como un análisis crítico, además de métodos cuantitativos para la obtención de datos generales a través del programa Not Just Analytics. Con base en las métricas de participación de Instagram para el proyecto Construcción + , se seleccionaron 4 publicaciones que permitieron el análisis de las interacciones públicas. Como resultado de los análisis realizados, se encontró que la tasa de participación del perfil fue del orden del 4,27\%; el promedio de me gusta por publicación fue igual a 30 y el promedio de comentarios fue igual a 6; la frecuencia de las publicaciones fue de 4,17 días; y, finalmente, se presentan los hashtags más utilizados en publicaciones. Por tanto, parece que el proyecto utiliza claramente el marketing de contenidos como una herramienta para crear relaciones duraderas y aportar conocimiento científico, más específicamente relacionado con la construcción civil, proporcionando a sus usuarios un lenguaje claro y de fácil comprensión.

Palabras clave: Divulgación científica; Marketing de contenidos; Hormigón; Instagram.

\section{Introdução}

A popularização da ciência e da tecnologia surge como uma oportunidade desafiadora tanto para estudiosos, quanto para cientistas, acadêmicos e profissionais que atuam no ramo. A temática voltada para a divulgação científica tem tomado os holofotes contemporâneos e a comunidade acadêmica reconhece a dimensão significativa de exercer a comunicação de modo assertivo em meio à sociedade. A divulgação de artigos, publicações em jornais, revistas, blogs, resumos, teses de doutorado, dissertações de mestrado, entre outros e a utilização das plataformas digitais para tais fins evidenciam atividades cada vez mais necessárias e úteis para o pesquisador (Almeida, 2019). Duas das mais desenvolvidas e potentes sociedades modernas, a saber, os Estados Unidos e o Canadá, julgam o investimento no estudo das estruturas de concreto como um dos campos mais relevantes vinculados à ciência e à tecnologia, especialmente no que diz respeito à obtenção e preservação da qualidade de vida da sua população e a hegemonia de seu parque industrial. Tais sociedades consentem que o acentuado conhecimento acerca do concreto é capaz de estabelecer e acondicionar a sua indústria na fronteira do conhecimento, oportunizando seu elevado potencial competitivo (Helene \& Andrade, 2010).

O concreto é o material que assume o ranking de maior utilização na construção civil mundial, geralmente 
apresentando em sua composição cimento portland, agregado miúdo, agregado graúdo e água. Suas vantagens técnicas e econômicas são exemplares, pois a maioria das suas aplicações oferece propriedades adequadas a um baixo custo. Diante disso, o setor da construção civil tem crescido de modo notável, e o concreto tem exercido potencial insigne como um dos principais responsáveis pelo desenvolvimento de estudos e investigações que viabilizem a construção de obras e empreendimentos cada vez maiores e mais duráveis. Para tal, existe a necessidade de se buscar alternativas no que diz respeito ao uso convencional e investir no que há de mais promitente, hodiernamente, no âmbito científico e tecnológico (Rodrigues, 2017).

Indubitavelmente, a construção civil e o próprio concreto têm experimentado consideráveis e significativas mudanças nos últimos 30 anos. O desenvolvimento de novos materiais e aditivos desencadearam múltiplas possibilidades para as obras de concreto, reverberando nas suas propriedades e na sua produtividade de execução (Calado et al., 2015). Rodrigues (2017) salienta que, saber mais sobre o concreto é de excepcional relevância, uma vez que por se tratar do material estrutural de maior utilização, sua magnitude torna-se ainda mais expressiva ante às diversas aplicações, funcionalidades e características mecânicas para o seu desempenho (Couto et al., 2013).

Diante da relevância desse material e de suas inovações tecnológicas, percebe-se a importância de divulgar conhecimentos atrelados ao mesmo. Sob esse aspecto, destaca-se o marketing de conteúdo, designado como uma importante ferramenta estratégica que consiste na criação e distribuição de conteúdos e assuntos relevantes que sejam concernentes a um determinado público-alvo e que também exerçam certa utilidade. Sua principal finalidade é fomentar a disseminação de conteúdo, uma vez que, dessa forma, há grandes chances de atrair e reter a(o) comunidade/público interessada(o). À vista disso, o contínuo repartimento de conteúdos trouxe possibilidades para que o marketing direcionasse seus aspectos estratégicos e criasse o marketing de conteúdo, um instrumento em que os conteúdos são denotados de forma precisa para o nicho que se deseja alcançar. E é por intermédio do uso das redes sociais on-line que há a ocorrência desse episódio, que de modo consequente, estimula a criação de páginas pelas marcas, visando a aproximação e a interação com o público. É válido salientar que os conteúdos retratados em tais páginas são reproduzidos em formatos de imagem, texto, vídeo, entre outros (Ramalho, 2016).

Nesse contexto, o projeto de extensão Construção + vinculado ao Instituto de Ciência, Engenharia e Tecnologia (ICET) da Universidade Federal dos Vales do Jequitinhonha e Mucuri (UFVJM) - Campus do Mucuri composto por docentes, técnicos e discentes voluntários da mesma instituição, além de permitir aos profissionais da construção civil do município de Teófilo Otoni a obtenção de informações teóricas e práticas mediante um programa de capacitação, o projeto em questão possui mídias sociais voltadas para a disseminação de conteúdos relacionados à indústria da construção civil por meio de plataformas tais como site, Instagram, blog, Facebook, You Tube, WhatsApp, Anchor e Spotify (no formato de podcast). Desse modo, esse estudo apresenta o seguinte problema de pesquisa:

- Como está caracterizada a utilização do marketing de conteúdo na plataforma Instagram pelo projeto Construção + na disseminação de temas inovadores acerca do concreto, a partir de uma análise crítica dos dados e do engajamento?

Nesse contexto, o presente artigo objetiva demonstrar que a divulgação científica relacionada às inovações do concreto pode ser desenvolvida por meio do marketing de conteúdo. A partir disso, foi realizada uma fundamentação teórica acerca dos conceitos de divulgação científica e marketing de conteúdo para estudar o engajamento com o conteúdo atrelado à importância das inovações relacionadas ao concreto, sendo tais conteúdos produzidos e publicados pelos colaboradores do projeto Construção + em sua página nas mídias/redes sociais. Dessa forma, foram selecionados posts que viabilizaram a análise das interações públicas feitas em cada publicação, assim como, utilizaram-se outros dados obtidos a partir do programa on-line Not Just Analytics, tendo como fundamento as métricas de engajamento fornecidas pelo canal Instagram. Com base nisso, foram explorados os indícios de engajamento com o conteúdo e as deduções de como essas informações dialogam com 
as definições teóricas de exercício da divulgação científica e da disseminação de conteúdo inovador na indústria da construção civil.

Ademais, a justificativa para o desenvolvimento da pesquisa abrange dois aspectos: o primeiro deles envolve a importância das inovações tecnológicas no âmbito da construção civil, em especial as invenções, aplicações e múltiplas funcionalidades do concreto, sendo esse um material de consagrado potencial em todo o mundo; e o segundo envolve a disseminação de conteúdos científicos relacionados a esse material de forma a se alcançar uma maior parte da comunidade, haja vista que muitas das vezes, pesquisas com conteúdo de grande relevância são retidas em repositórios e não divulgadas como uma oportunidade para o crescimento e popularização da ciência e da tecnologia, que a cada dia se expande e instiga o impulsionamento de novos conhecimentos e estudos que viabilizem o desenvolvimento científico e tecnológico.

O presente artigo está estruturado nas seguintes seções: introdução com a contextualização do estudo, problema, objetivos da pesquisa e justificativa; referencial teórico; métodos e técnicas aplicados à pesquisa; análise de dados - análise crítica; considerações finais e referências.

\section{Métodos Aplicados na Pesquisa}

A pesquisa em questão atrela-se à natureza descritiva, uma vez que consiste na observação e investigação de fatos e fenômenos, procurando a sua descrição, classificação e interpretação. Segundo Vieira (2002), a pesquisa descritiva tem como função apresentar as características de uma determinada população ou de determinado fenômeno, entretanto, não se responsabiliza em explicar os fenômenos que descreve, embora sirva de suporte para tal explicação. Além disso, esse tipo de pesquisa pode exercer interesses voltados para as relações entre variáveis e, dessa forma, aproximar-se das pesquisas experimentais.

O delineamento foi elaborado a partir de uma revisão bibliográfica em livros, artigos, revistas, dissertações, teses e documentos afins relacionados à divulgação científica, marketing de conteúdo e inovações tecnológicas relacionadas à construção civil, em particular, ao concreto. De acordo com Fonseca (2002), qualquer trabalho científico desenvolve-se inicialmente por meio de uma revisão bibliográfica, tendo em vista que a mesma permite ao pesquisador conhecer os assuntos e abordagens relacionadas ao assunto em estudo/análise. É válido salientar que essa revisão contribuiu para o embasamento literário voltado para as temáticas centrais do artigo, constituindo os capítulos teóricos.

Quanto aos métodos aplicados na pesquisa, foi realizada uma abordagem quanti-qualitativa com o intuito de investigar e compreender o que os critérios de métrica de engajamento utilizados pelas mídias sociais, em especial o Instagram, podem indicar a respeito da divulgação científica nas mídias sociais de modo on-line. Gil (2017) explica que nas pesquisas quantitativas, os resultados são expressos em termos numéricos, enquanto na pesquisa qualitativa, a representação é feita mediante descrição verbal. Ademais, essa pesquisa também pode ser considerada como sendo de natureza aplicada, já que está vinculada à obtenção de conhecimentos voltados para aplicação prática numa situação particular, sendo tais conhecimentos dirigidos à solução de problemas específicos.

Quanto à coleta de dados, utilizaram-se técnicas de pesquisa documental, a qual apresenta aspectos similares à pesquisa bibliográfica. Essas duas modalidades caracterizam-se pela utilização de informações já existentes (Gil, 2017). O autor citado enfatiza que a pesquisa documental está vinculada a todo e qualquer documento desenvolvido com múltiplos interesses, tais como assentamento, autorização, comunicação, entre outros. Nesse aspecto, o presente artigo utilizou-se de materiais elaborados para fins de divulgação, no caso, publicações na plataforma do Instagram, sendo essas consideradas como documentos em pesquisas no campo comunicacional.

Assim sendo, o presente trabalho consistiu em analisar 4 posts do Instagram do projeto Construção + entre outros 
dados obtidos por meio da plataforma on-line e gratuita: Not Just Analytics. O programa citado permite buscar e analisar qualquer conta do Instagram e, posteriormente, apresenta várias métricas acerca daquele perfil. Nesse caso, os dados extraídos foram: número de seguidores e de publicações; média de curtidas e comentários do perfil; taxa de engajamento; frequência de posts e uma nuvem de palavras com as hashtags mais utilizadas pelo projeto.

Em relação à delimitação do objeto de estudo, procedeu-se da seguinte forma: os conteúdos selecionados para análise tinham, obrigatoriamente, que apresentar temas relacionados ao concreto, resumo sobre o conteúdo, além do mais, possuir embasamento em pesquisas científicas, não exclusivamente, a fim de proporcionar maior credibilidade. É importante salientar que no Instagram não há o indicativo das fontes utilizadas para a construção da matéria, por isso foi investigado também o blog do projeto com o único intuito de verificar as fontes utilizadas. Ademais, verificou-se as datas em que esses conteúdos foram veiculados, o número de curtidas e de comentários de cada post, bem como uma análise crítica dos mesmos.

De acordo com informações do site do Construção +, o projeto em questão surgiu com o intuito de proporcionar aos profissionais da construção civil do município de Teófilo Otoni acesso a informações teóricas e práticas mediante um programa de capacitação. Como benefícios, o projeto está diretamente ligado à área de ensino, uma vez que os discentes do projeto são os próprios instrutores do curso. O projeto Construção + está vinculado ao Instituto de Ciência, Engenharia e Tecnologia (ICET) da Universidade Federal dos Vales do Jequitinhonha e Mucuri (UFVJM) - Campus do Mucuri formado por docentes, técnicos e discentes voluntários da mesma instituição. Além de se apresentar como curso presencial, o projeto está presente em plataformas como site, Instagram, blog, Facebook, YouTube, WhatsApp, Anchor e Spotify (no formato de podcast) com fins voltados à disseminação e o compartilhamento de informações relacionadas à indústria da construção civil, em particular. Nas mídias sociais Instagram e blog, por exemplo, são publicados uma variedade de conteúdos teóricos com temáticas do âmbito construtivo, a fim de difundir o conhecimento científico e atrair a comunidade como um todo (Construção + , n.d.).

\section{Divulgação Científica}

A ciência no Brasil enfrenta grandes desafios, é perceptível que boa parte da população ainda apresenta desinteresse pelas temáticas tratadas em pesquisas recentes. Isso se deve, em parte, pela dificuldade em compreender as bases científicas ao longo do ensino básico e, por outro lado, pela falta de contato com a divulgação científica. Na área científica é comum lidar com temas muito específicos e, normalmente, de difícil visualização e associação. Dessa maneira, torna-se mister para a divulgação da ciência criar pontes entre a linguagem presente na academia e a linguagem do cotidiano das pessoas. Além do mais, espera-se que o assunto seja situado e contextualizado, de modo que os indivíduos sejam capazes de perceber as implicações de uma descoberta científica na vida da população comum (Jurno, 2017 \& Alencar, 2018).

Por outro lado, de acordo com Ivanissevich (2009) é parte indissociável da missão dos pesquisadores a popularização da ciência como uma maneira de prestar contas à sociedade e, para além disso, demonstrar a real necessidade de se investir em ciência e o quanto isso pode ser proveitoso para toda a sociedade. Frente a essa perspectiva, nas últimas décadas, o Brasil vem expandindo seus canais de divulgação científica e sendo promovido a um despertamento ocasionado pela transformação digital capaz de ser constatado na diversificação dos setores sociais. O mundo se converteu numa aldeia global conectada pela Internet. A produção de materiais e conteúdos e sua disseminação em websites, blogs e redes sociais, hoje, é sinônimo de benefício estratégico e efetivo para profissionais de diferentes setores. No âmbito acadêmico, caso o pesquisador não usufrua das redes sociais como recurso profícuo para difundir seus projetos e pesquisas, poderá desperdiçar oportunidades e vantagens atreladas à atração de financiamentos, popularização da ciência e também a chance de se tornar referência em suas respectivas áreas à frente da sociedade e do mercado em que está inserido (Almeida, 2019). 
Na medida em que a ciência e a tecnologia avançam, dão origem à documentação abrangente e diversificada, em que textos inobstante da sua natureza, em meios impressos ou eletrônicos, apresentam traços peculiares nos aspectos: semiótico, pragmático, sintático, semântico e, acima de tudo, lexical. Segundo Barros (2006), graças à especificidade da terminologia é que esses textos proporcionam a veiculação de novos fundamentos e conhecimentos especializados. Todavia, para que os resultados científicos alcancem a comunidade e a população como um todo é crucial a utilização do processo de divulgação científica ou divulgação da ciência (Targino, 2007).

A temática em questão se encontra num contexto que está diretamente associado a concepções que transcorrem a comunicação da ciência, aqui compreendida ainda em termos subordinados ao universo acadêmico. A ascensão da Internet, em um primeiro instante, trouxe como provento a disseminação da ciência e, como efeito, revelou os impactos científicos e tecnológicos incorporados ao desenvolvimento e às transformações sociais em diferentes aspectos, como na economia, educação, comunicação, entre outros. Ante o exposto, no presente, a sociedade se apodera de uma perspectiva em que é praticamente considerada como uma utopia a visualização do mundo sem a Internet e, sobretudo, um meio social em que mundo off-line e on-line não colidam. Os modos de diálogo, informação e mobilização estão firmemente alicerçados no que a Internet se dispõe a oferecer. Essas características de interação oportunizadas pela Internet exercem extrema importância a partir do momento em que se pensa na comunicação, tendo em vista a permissão de que o sujeito atue na capacidade de assumir seu protagonismo como cidadão, acessando, promovendo questionamentos e inter-relacionando-se com o conteúdo. E é por meio das mídias digitais que tal processo se torna possível no presente, como também se faz em um ritmo frenético que expressa os deveres da produção de conteúdo e da multiplicação de novos conhecimentos (Mariano, 2019).

Sob esse aspecto, as autoras Ferreira e Chiaretto (2016) apresentam o marketing de conteúdo, que em síntese, caracteriza-se como uma aplicação estratégica para criação e distribuição de conteúdo importante e de valor para um público, através de variados meios de comunicação com o intuito de atrair, conquistar e envolver esse público e, por fim estabelecer um vínculo que possa ser rentável. Nesse contexto, as estratégias e ferramentas do marketing de conteúdo proporciona ótimas oportunidades para que os profissionais da academia, pesquisadores e cientistas divulguem seus trabalhos e contribuam com a disseminação da ciência e da tecnologia e os seus impactos, sejam eles positivos ou negativos, para conhecimentos da sociedade (Almeida, 2020).

Assim, o avanço de pesquisas, de estudos e do conhecimento tem propiciado, nos últimos anos, uma extensa sofisticação da ciência e da tecnologia de materiais hoje utilizada para o aperfeiçoamento e desenvolvimento de materiais otimizados, com fins atrelados ao cumprimento das funções desejadas com excepcional eficiência. O concreto de cimento portland é designado como o material de maior uso na construção civil mundial, pois seus benefícios técnicos e econômicos são, indubitavelmente, sua marca registrada. Além do mais, grande parte das suas aplicações apresentam propriedades apropriadas a custos reduzidos. Desse modo, um maior conhecimento acerca do concreto é de grande importância, especialmente quanto à divulgação de inovações com esse material destinadas à sua utilização na indústria da construção civil. Isso graças à potencialidade dessa tecnologia na melhoria de inúmeros materiais de construção, tais como: aços estruturais, polímeros, materiais cerâmicos e, sobretudo, materiais cimentícios (Rodrigues, 2017).

Logo, percebe-se a relevância e o destaque relacionados à divulgação científica, tendo em vista que tal ferramenta exerce um papel crucial sob inúmeras vertentes, pois o acesso ao conhecimento científico favorece o desenvolvimento social, colabora com o avanço qualitativo vinculado à formação educacional e oportuniza a população no que diz respeito à aproximação gradativa do conteúdo científico. Esses aspectos promovem aos indivíduos o contato com a produção científica em um cenário informal, tornando a divulgação científica um significativo meio de inclusão social, levando em consideração que essa prática contribui com a ampliação e desenvolvimento da cidadania. Nesse caso, o conhecimento científico acerca do concreto revela-se como de extrema relevância, uma vez que esse material por ser utilizado em grande escala no âmbito 
construtivo, destaca-se pelas suas características e alta performance, tais como: resistência a intempéries, visto que esse é inserido a diferentes condições climáticas; resistência mecânica; ótimo desempenho e trabalhabilidade ao ser moldado, além de assumir diversas geometrias. Por conseguinte, verificam-se vários benefícios decorrentes de pesquisas científicas, em particular, a geração de conhecimentos que amparam o desenvolvimento de novos mecanismos e aparatos tecnológicos essenciais e convenientes à sociedade, especialmente no que diz respeito ao concreto.

\section{Marketing de Conteúdo}

Perante o cenário moderno, em que os aparatos tecnológicos e os modos de se comunicar, informar e agir em sociedade se transformam regularmente, surge como vertente o marketing 4.0, conceituado pelo estudioso autor da área de economia, Philip Kotler. Nesse novo paradigma, o grande desafio está atrelado à criação e desenvolvimento de planejamentos estratégicos que abracem um espaço comunitário cada vez mais bombardeado de fomentos externos e que apresentam como característica principal a necessidade de rapidez. Por esse motivo, Kotler, Kartajaya \& Setiwan (2017) fazem referência à essência do marketing 4.0 como motivo de reconhecimento das modificações de funções do marketing convencional e digital na produção de mecanismos voltados para o engajamento. Para o alcance desse objetivo, diferentes setores da sociedade têm investido no marketing de conteúdo.

O marketing de conteúdo é uma ferramenta dentro do marketing que está ganhando grande visibilidade e popularidade devido aos avanços tecnológicos e o desenvolvimento da Internet nos últimos anos, que modificou consideravelmente a forma como as pessoas se relacionam e se comunicam. Percebe-se que o marketing se apropriou da interatividade propiciada pela tecnologia para criar canais de comunicação bidirecionais com os atuais clientes, bem como, com aqueles clientes potenciais. Hodiernamente, é bastante comum os clientes utilizarem as mídias digitais para buscarem soluções para os seus problemas e, para atender a essas necessidades, é de suma importância que as organizações criem conteúdos capazes de auxiliar os mesmos, assim como, utilizem mecanismos de pesquisa para que possam ser encontradas no momento certo. Quando as informações são relevantes e valiosas, isso contribui para uma percepção positiva da marca e contribui na criação de consciência e lealdade à mesma, bem como, auxilia no processo de conquista de novos clientes (Vinerean, 2017 \& Yaghtin, Safarzadeh \& Zand, 2020).

Essa metodologia pode ser definida como "uma abordagem de marketing estratégico focado na criação e distribuição de conteúdo valioso, relevante e consistente para atrair e reter um público claramente definido" (Content Marketing Institute [on-line], n.d.). Dessa forma, ao utilizar o marketing de conteúdo as organizações não objetivam promover e enfatizar os benefícios de um produto ou serviço específico, mas, sim, entregar valor para as pessoas por meio de conteúdos que ajudem na solução dos seus problemas ou que tragam algum entretenimento e diversão para quem os consome.

$\mathrm{Na}$ atual conjectura, a atenção das pessoas e, por conseguinte, os investimentos em publicidade estão fragmentados em diferentes tipos de mídia, a saber: jornais impressos, rádio, televisão, sites de notícias on-line, blogs, plataformas de mídia social, e-mail, fontes de vídeo on-line, entre vários outros. Todas essas possibilidades de mídias corroboram a postura dos indivíduos em acessar informações de diversas direções. Sendo assim, visando atingir grande parte do público, é imprescindível que as organizações disseminem conteúdos em vários gêneros e formatos como, por exemplo, vídeos, textos comunicativos, imagens, áudios e também busquem utilizar diferentes plataformas (Wall \& Spinuzzi, 2018).

Um dos grandes benefícios desse tipo de abordagem, é o fato dessas plataformas não apresentarem uma estrutura igual às fontes tradicionais, isso porque as empresas não precisam alugar ou comprar determinado espaço a fim de compartilhar conteúdos pertinentes lá. Logo, é possível postar conteúdos nos espaços pertencentes às empresas como sites, bem como, nas mídias sociais gratuitas tais como Twitter, Facebook ou Instagram. Outro aspecto relevante e que deve ser 
enfatizado é o valor do conteúdo e sua aderência ao perfil do mercado-alvo, uma vez que o marketing de conteúdo preconiza que as pessoas devem consumir o conteúdo de maneira espontânea, e, além do mais, devido à estrutura interconectada da web, com vários hiperlinks, é extremamente fácil contornar conteúdos censuráveis ou sem relevância (Wall \& Spinuzzi, 2018).

Torna-se importante salientar que o marketing de conteúdo não é um ramo da publicidade. A produção de conteúdos relevantes é uma estratégia dentro do marketing, a qual busca desenvolver relacionamentos com os clientes e, ao mesmo tempo, desenvolver uma imagem positiva da organização (Rez, 2016).

O marketing de conteúdo é extremamente necessário, uma vez que melhora todo o marketing de um negócio. Isso se deve ao fato dele ser capaz de integrar e centralizar todas as outras estratégias. Somente o conteúdo participa das várias etapas do marketing. Por exemplo, quando um e-mail é encaminhado a um cliente, o mesmo é composto por uma mensagem escrita ou possui um formato de imagem, o que representa um tipo de conteúdo. Da mesma forma, quando as empresas trabalham com marketing de afiliados, é necessário desenvolver conteúdo para ensinar e educar os indivíduos a revenderem um determinado produto. Além do mais, quando as instituições procuram maneiras de otimizar seus sites por meio de melhorias em suas posições nos motores de busca e fazendo com que sejam mais significativos, por intermédio do Search Engine Optimization (SEO), isso somente é alcançado com base em conteúdos bem indexados, compartilhados e consumidos. Portanto, claramente, é possível constatar que nenhuma outra estratégia de marketing digital, agindo sozinha, é qualificada para alimentar e estruturar todas as outras como o marketing de conteúdo (Rez, 2016).

Dito isso, é importante destacar, conforme Costa \& et al. (2016), que o marketing é um processo de planejamento, implementação, análise e controle de programas, além do mais, o mesmo fomenta trocas entre grupos sociais e pessoas. Portanto, hodiernamente, não se restringe apenas a atividades comerciais, que visam somente o lucro. Sob tal vertente, destacam-se as universidades e faculdades, que podem utilizar o marketing de conteúdo digital como meio de construção da marca. Visto que os indivíduos utilizam, cada vez mais, a mídia eletrônica a fim de interagirem com as marcas e, associado a isso, a tendência de selecionar com quais conteúdos se engajam, é fundamental que as universidades e faculdades invistam em modelos de branding fundamentados em conteúdo de marca envolventes e valiosos (Pharr, 2019).

Assim, com base em uma revisão de literatura, Pharr (2019) elenca uma série de boas práticas que podem ser adaptadas pelas instituições de ensino superior, com o propósito de implementar o marketing de conteúdo digital, a saber: estabelecer quais são os objetivos do programa de marketing de conteúdo; enfoque no conteúdo que atenda às necessidades do público; mesclar conteúdo de marca e sem marca para ampliação do impacto ocasionado pela marca da instituição e a incorporação de conteúdos visuais com o objetivo de impulsionar o envolvimento das pessoas.

De acordo com Grainge (2017), ao passo que as universidades se constroem como marcas perante uma "economia do conhecimento" amplamente competitivo, é possível constatar o quanto essas instituições, com o decorrer do tempo, têm procurado investir em maneiras de narrar histórias acerca da pesquisa, comunidade, aprendizagem e experiência do aluno. O autor traz o exemplo de vídeos curtos que foram produzidos na universidade de Nottingham, Reino Unido, e disponibilizados no YouTube, cujo intuito, por meio da execução de experimentos peculiares, era apresentar os 118 elementos da tabela periódica, em que cada um desses elementos foi apresentado em vídeos distintos. A partir desse exemplo, é possível notar que as universidades podem, e devem, explorar as possibilidades dos recursos digitais, como no caso supracitado em que a universidade optou pelo YouTube (na maioria das vezes, sem descartar as outras plataformas), para levar até o público os conhecimentos científicos de novas maneiras. Ademais, o desenvolvimento desses curtas digitais, que podem ter aspectos tanto divertidos quanto informacionais e de utilidade, pela universidade, são enfatizados cada vez mais a fim de engajar e envolver o público-alvo da instituição.

Da mesma forma, os periódicos científicos podem lançar mão do marketing digital, termo que engloba o marketing de conteúdo, como colaborador na divulgação da imagem do próprio periódico, assim como, no compartilhamento dos conteúdos 
publicados no periódico, por exemplo, artigos, relatos de experiência, relatos de pesquisa, pontos de vista/comentários, entrevistas, memórias de eventos técnico-científicos, entre outros e, além do mais, possibilita a constante interação com os leitores. Entende-se que a realização do marketing digital por intermédio da utilização de mídias sociais pelos periódicos é uma necessidade, uma vez que esses já nascem num âmbito eletrônico e, aliado a isso, o fato de o público-alvo estar progressivamente mais conectado e inserido na esfera das mídias sociais (Costa \& et al., 2016).

As ações para a estratégia de conteúdo envolvem o planejamento da criação, a publicação e a regência de conteúdo utilizável e útil. De acordo com os autores, deve-se ter atenção tanto em relação ao objetivo do conteúdo a ser desenvolvido, quanto à pretensão do alcance de sua publicação, para que tais vertentes proporcionem valor e venham somar conhecimentos. O conteúdo a ser divulgado é um recurso crítico e deve ser implementado com o planejamento estratégico e investimentos importantes. Desse modo, tal recurso deve alcançar reações significantes ao seu leitor, cliente ou financiador, assim como as metas do pesquisador, sobre a sua criação, uma vez que sejam alcançadas e revelem a sua importância e contribuição para com a sociedade (Ferreira \& Chiaretto, 2016 apud Halvorson, 2012).

Logo, percebe-se que o marketing de conteúdo ganha cada vez mais espaço e não é para menos, já que essa metodologia agrega valor às relações e trocas entre variadas instituições e pessoas comuns. No entanto, é relevante salientar que essa abordagem não se restringe somente a ambientes de negócios, uma vez que pode ser utilizada por universidades, faculdades, dentre outras instituições e entidades afins como um caminho capaz de impulsionar a transmissão do conhecimento científico e evitar que esse conhecimento valioso fique restrito. No caso deste estudo, cujo intuito é explorar a geração de conteúdos relacionados às inovações do concreto de modo a apontar os novos conhecimentos dessa temática que surgem no âmbito da academia, o marketing de conteúdo ainda pode proporcionar a distinção das marcas dessas instituições, bem como, vantagens competitivas.

\section{Inovações dos Materiais da Construção Civil}

A indústria de materiais de construção tem apresentado anseios por inovação com o objetivo de eliminar os desperdícios na cadeia produtiva, assim como a sustentabilidade na construção civil em resposta à cobrança do governo, do mercado e da sociedade, a fim de obterem uma visão de organização positiva em vez de críticas com as vertentes ambientais. Hodiernamente, a sustentabilidade custa um valor alto às indústrias da construção, uma vez que a maioria das fontes de seus recursos são extraídas da natureza, além da elevada geração de resíduos (Sattler, 2002 \& Costa \& Nascimento, 2011).

O desenvolvimento de novos produtos e a sua inovação são questões centrais para indústrias ponderadas. Assim como a sua longevidade de produção, seus produtos seguem com a mesma perspectiva, em paralelo, com uma produção usufruindo da tecnologia certa e uma demanda estável. A inovação deve ser coerente, precisa e constante. No entanto, cada organização e o seu planejamento de um projeto é particular, tendo em vista que cada produto, mercado e tecnologia exigem diferentes estruturas e processos organizacionais (Costa \& Nascimento, 2011).

No presente, grande parte dos estudos científicos e tecnológicos tem se voltado constantemente para a análise e o desenvolvimento de novos materiais relacionados ao campo da construção civil. Nesse contexto, salienta-se o concreto de cimento portland, que por sua vez, tem sido gradualmente utilizado nas obras de construção em todo o mundo, como em edificações modernas, infraestrutura de tráfego e construções marítimas (Zhu \& et al., 2020). Caracterizado como um dos principais avanços tecnológicos mais importantes da história da construção civil e da humanidade, foi graças a esse material que o século XX pôde contemplar a consolidação e o desenvolvimento da construção de inúmeras cidades ao redor do mundo. Ademais, os estudos científicos voltados para a aplicação do concreto exerceram uma contribuição significativa para o progresso das ciências e das tecnologias empregadas nos materiais como um todo (Shi, Jiménez \& Palomo, 2011). 


\subsection{Concreto colorido}

O concreto é o material de maior produção no mundo, uma vez que o seu uso nas execuções de obras de engenharia corresponde por suas características específicas quanto à sua qualidade. A resistência deste produto à deterioração lhe confere vantagens em relação ao aço e à madeira. Além de apresentar ótima resistência à água e assumir diferentes geometrias ao ser aplicado, o concreto é classificado como um material de baixo valor e a sua produção é rápida quando solicitada. Basicamente, o concreto pode ser descrito como uma dosagem de agregados, água e cimento portland (Mehta \& Monteiro, 2014).

O concreto colorido compõe uma das classes de concreto aparente. O detalhe encontra-se na produção do concreto dotado de cor, em que suas extensões expostas proporcionam acabamento à superfície. O concreto colorido requer um controle tecnológico a fim de avaliar suas propriedades para aplicação estrutural, visto que o mesmo proporciona excelentes terminações arquitetônicas, colaborando com um desenvolvimento construtivo ágil. O emprego do concreto colorido pode ser notado em elementos estruturais construtivos, como vigas e pilares, pavimentos flexíveis intertravados coloridos e as vias para atividade pública, como as ciclovias (Valença \& Priszkulnik, 2017).

Os pigmentos que conferem cor ao concreto são minerais ou orgânicos, uma vez que os mesmos podem ser classificados conforme o seu material de origem. Pigmentos à base de água são definidos como pigmentos orgânicos e os pigmentos à base de óxido de ferro são definidos como inorgânicos. Os pigmentos inorgânicos apresentam tonalidade de qualidade e resistência às ações de intempéries e, além disso, são insolúveis à composição do concreto, permanecendo as características do tom aplicado. As nuances à base de óxidos de ferro são diversas, podendo apresentar tonalidades em vermelho, terra, laranja, amarelo, areia, ocre, marrom, preto. Os aditivos coloridos também são empregados para aplicar cor às telhas, argamassas, blocos, rejuntes e pisos (Aguiar, 2006).

Na Universidade Federal dos Vales do Jequitinhonha e Mucuri (UFVJM) - campus Mucuri, município de Teófilo Otoni, existe um grupo de pesquisa intitulado Geovales, dentre os trabalhos realizados, está a análise do concreto colorido produzido com os agregados de rocha local. O cimento é o material de maior influência na resistência à compressão do concreto, enquanto o aditivo colorido exerce uma interferência, contribuindo para a diminuição dessa propriedade. Diante disso, em Sousa, Oliveira \& Gomes (2020), o concreto colorido com o teor de 3\% de pigmento para um traço com a resistência à compressão de $40 \mathrm{MPa}$ aos 28 dias de cura, obteve uma boa performance no ensaio de compressão, alcançando o valor de resistência igual a $38,25 \mathrm{MPa}$, portanto, vale ressaltar que o traço com elevada quantidade de cimento, apresentou-se menor interferência provida da adição do óxido de ferro.

De acordo com os autores Souza, Rocha \& Gomes (2020) os agregados de rocha utilizados na construção civil do município de Teófilo Otoni são caracterizados pela presença do mineral biotita na sua composição, essa característica pode influenciar e alterar as propriedades do concreto. Promovendo o avanço do concreto colorido, os autores obtiveram os melhores resultados com a concentração de 3\% de pigmento, os traços produzidos com o percentual mais elevado, sendo esses respectivamente concentrações de $5 \%$ e $6 \%$, contribuíram para dificultar a trabalhabilidade da mistura de concreto fresco, assim como a diminuição da resistência à compressão. Assim, ressalta-se que o traço referente ao percentual de $3 \%$ do aditivo colorido propiciou os melhores resultados, sendo esse teor o mais recomendado para a produção de concreto colorido em Teófilo Otoni.

A busca por materiais na engenharia com alto desempenho e tecnologia, otimização do custo, controle de produção e o desenvolvimento de ações sustentáveis tem chamado cada vez mais a atenção dos pesquisadores e do mercado. Nesse aspecto, o concreto colorido, constituído a partir do concreto convencional e apresentando aditivo colorido para a construção civil na sua composição, fomenta uma tecnologia promissora ao concreto. Além de eliminar o uso de materiais para fins arquitetônicos, a aplicação do concreto colorido proporciona o avanço das construções e pode ser observado por todo o mundo. Edifícios construídos com o respectivo material exibem um belo acabamento arquitetônico, ainda que seja carente de 
investigações quanto ao seu comportamento mecânico.

\subsection{Concreto translúcido}

Dentre as novas inovações para o desenvolvimento do concreto, surge no ano de 2001 o concreto translúcido. A inspiração para esse material sucedeu-se a partir das observações feitas pelo arquiteto húngaro Áron Losonczi, da obra de arte desenvolvida pelo artista romeno Varga St. Luigi, sendo composta de bloco de concreto com vidro, que proporcionou uma nova estética para a superfície de acabamento. O concreto translúcido ou Light Transmitting Concrete consiste numa combinação de fibras ópticas e concreto, referente a concentrações de $95 \%$ de concreto e $5 \%$ de fibra óptica. As fibras apresentam um tamanho pequeno e se misturam ao concreto como um agregado, apresentando um material homogêneo. Essa inovação para a área dos materiais da construção proporciona valor técnico e estético (Giacomelli \& Mantovani, 2014).

Em decorrência das suas particularidades, sua combinação permite que o concreto exerça a capacidade de transmitir luz, percorrendo por toda a sua espessura. Esse material contribui para a economia da energia elétrica devido à sua capacidade do aproveitamento da fonte de iluminação natural, isto é, a luz solar, iluminando todo o ambiente interno da edificação. A incorporação da fibra óptica à matriz do cimento não proporciona interferências da resistência à compressão, característica do concreto estrutural. A superfície do concreto translúcido lembra a do concreto tradicional, no entanto, surpreende ao ser atingida pela luz em um dos seus lados, transportando-a para a outra superfície. Os autores apresentam as fibras ópticas como filamentos de material transparente, sendo as matérias-primas o vidro, que pode ser inorgânico ou amorfo, assim como os materiais poliméricos, de origem orgânica ou sintética com diâmetros distintos. A fibra óptica transmite a luz de um lado ao outro mediante sucessivas reflexões (Giacomelli \& Mantovani, 2014).

\subsection{Bioconcreto}

O concreto encontra-se inserido em diversas condições climáticas, por conseguinte, sujeito à deterioração devido às diferentes ações dos agentes intempéricos. Além disso, o concreto assume propriedades mecânicas que proporcionam a segurança de uma obra de engenharia. O surgimento de aberturas, denotadas como fissuras, indicam o surgimento de manifestações patológicas no concreto. Diante disso, a técnica Microbial-Induced Carbonate Precipitation (MICP) vem sendo desenvolvida e empregada com a função de diminuir as aberturas no concreto, classificadas como fissuras. O seu uso consiste no bioconcreto, material de cimentação, esse também proporciona boa resistência à compressão, e a outra forma de uso é a biodeposição, camada superficial de proteção. As fissuras possibilitam a entrada de água na estrutura, diante da umidade, os microrganismos despertam e dão início a biomineralização, esse processo libera o cálcario que preenche as aberturas, portanto, contribui para a regernaração da superfície. As bactérias incorporadas ao concreto contam com o lactato de cálcio, o qual é utilizado para alimentação desses microrganismos (Silva, Passarini \& Santos, 2017).

O processo biogeoquímico MICP consiste num processo natural de ocorrência no solo a partir da precipitação do carbonato de cálcio, unindo grãos de areia e estruturando o solo, tornando-o mais resistente. Essa técnica vem sendo aplicada para resolver problemas ambientais e na construção civil, proporcionando proteção ao concreto e às argamassas. A biomineralização consiste em um método no qual os microrganismos vivos precipitam em tipos de minerais inorgânicos. Diante disso, um dos mais investigados é a biomineralização do carbonato de cálcio $\left(\mathrm{CaCO}_{3}\right)$, produto de secreção das atividades metabólicas bacterianas. Uma diversidade de bactérias possui a capacidade de liberar cristais de $\mathrm{CaCO}_{3}$ quando cultivadas no meio de cultura com fonte de cálcio, tal como o lactato de cálcio (Reis, 2017). 


\subsection{Concreto leve}

A busca pelo desenvolvimento através de pesquisas do concreto e a adição de novos materiais em sua dosagem viabilizam qualidades alternativas aos concretos convencionais. Diante disso, surge o concreto leve, caracterizado pela alta performance de características como a massa específica e ao conforto térmico, em virtude de diminuir a absorção e transferência do calor proveniente da radiação solar, juntamente com a possibilidade de aplicação para manutenção da resistência mecânica. A diminuição da massa específica, redução de esforços estruturais, economia de fôrmas e redução de custos com o transporte e a montagem, são as principais vantagens desse material (Angelin, 2014).

Os concretos leves podem apresentar quatro classificações, respectivamente, concreto com agregado leve, correspondente à aplicação total ou parcial de agregados leves, sendo esse o único que possa vir a alcançar valores de resistência aceitável para a aplicação estrutural; o segundo consiste no concreto celular ou aerado, correspondente à adição de produtos que reagem produzindo bolhas de ar no concreto fresco, salientando-se que essa técnica gera discórdia quanto ao seu uso, justificando que o material resultante encontra-se na pasta e não necessariamente no concreto; a terceira classe de concreto leve é o concreto sem finos, sua produção com agregados graúdos e aglomerante, retirando os finos do traço, sua resistência passar-se-á da resistência do agregado e ao cimento utilizado; ainda pode-se apresentar um quarto tipo de concreto leve, o concreto leve misto, produto de uma dosagem com agregados leves, aditivos incorporadores de ar e a redução do peso dos finos (Angelin, 2014).

\subsection{Adições minerais no cimento portland}

A fabricação do cimento portland exige a associação de matérias-primas, não misturadas naturalmente, em suas respectivas quantidades e com processamento mais extenso se comparado ao cimento natural (Aïtcin, 2016). O cimento portland é caracterizado por estar atrelado a uma classe de materiais que geralmente assemelham-se a um pó cinza composto de vários minerais e que com base nessa composição, pode ser dividido em várias categorias, sendo elas: cimento portland comum; cimento de aluminato; cimento de sulfoaluminato, cimento de fluoaluminato e cimento de ferroaluminato (Pratt \& Jennings, 1981). O mais utilizado é o cimento portland comum em virtude da sua disponibilidade acessível (Zhu \& et al., 2020). Devido ao seu consumo em grande escala, evidencia-se o surgimento de inúmeros desafios, como a escassez de matérias-primas provenientes da natureza, o elevado consumo de energia e a liberação de $\mathrm{CO}_{2}$ na atmosfera (Moberg \& et al., 2005).

Nesse contexto, há uma enorme quantidade de resíduos sólidos gerados pela indústria, o que induz a ocorrência de problemas ambientais em virtude da sua elevada alcalinidade, lixiviação de metais pesados ou partículas com finura acentuada. $\mathrm{Na}$ literatura, diversos autores têm fomentado a integração das duas questões abordadas acima na política de desenvolvimento da indústria de cimento por intermédio do reaproveitamento de resíduos industriais contendo elementos como cálcio, silício, alumínio, ferro, lítio e outras matérias-primas alternativas para a produção de clínquer de cimento. Do ponto de vista ambiental a reutilização desses resíduos é amplamente eficaz, visto que essa ação repercute na minimização dos índices de degradação causados outrora pelo descarte dos mesmos (Tan \& et al., 2019 \& Zhu \& et al., 2020).

No que diz respeito à obtenção de benefícios técnicos, econômicos e ambientais, a indústria cimentícia vem utilizando, ao longo dos anos, adições minerais em substituição parcial ao cimento portland. Além de vantagens como redução de custos e melhor desempenho das características do cimento, os aditivos minerais proporcionam um desenvolvimento sustentável relativo à cadeia de produção cimentícia, uma vez que tais adições oportunizam a reutilização de subprodutos e rejeitos gerados pela indústria, reduzem o lançamento de gases poluentes danosos ao meio ambiente e atenuam os gastos de energia durante o seu processo de fabricação, e por vezes, propiciam a redução do consumo de recursos naturais não renováveis (Garcia \& et al., 2014). 
Segundo Barbosa (2017), as adições minerais têm sido o escopo de inúmeras pesquisas e estudos em virtude da sua potencialidade quando em incorporação às matrizes cerâmicas, betuminosas e cimentícias, em que ocorre a busca pelo aumento da resistência mecânica, vida útil do material/longevidade e minimização da utilização de agregados ou compostos aglomerantes. Essas aplicações estão associadas ao desempenho físico que tais materiais exibem, atuando como filler, ou seja, preenchendo os poros e proporcionando um melhor empacotamento do sistema. A adição desses materiais, além de reagirem à expansão provocada pela reação álcali-agregado - reação físico-química capaz de promover a deterioração das estruturas de concreto sob determinadas condições de exposição -, favorece outras propriedades do concreto, como a permeabilidade, a resistência ao calor, a difusividade, entre outros, graças à presença de partículas sólidas de menor grandeza (Almeida, 2020).

Nesse contexto, a adição de minerais no cimento portland se caracteriza como uma possibilidade pertinente e promissora e de grande potencial, tendo em vista a redução de problemas ambientais e também o desenvolvimento de novas tecnologias empregadas em materiais. Tais aspectos, além de contribuírem de forma significativa à sustentabilidade, são assinalados e qualificados como inovações tecnológicas associadas ao concreto, trazendo inúmeros benefícios e vantagens tanto para a indústria da construção civil, quanto para a comunidade como um todo. Em síntese, a utilização de adições minerais também pode ser vantajosa por proporcionar aumento da resistência mecânica e durabilidade, redução dos custos e o aproveitamento dos resíduos industriais. Essas são umas das razões mais relevantes para o uso dessas adições na produção e complementação do cimento, tendo em vista a capacidade de gerar como produto final um concreto de maior qualidade, desempenho e trabalhabilidade.

\section{Resultados e Discussão}

A preocupação desta seção, no primeiro momento, dar-se-á em função de analisar os dados retirados da plataforma Not Just Analytics, em que se espera encontrar informações gerais acerca do perfil do projeto Construção + na plataforma Instagram. Posteriormente foi realizada uma análise crítica, no intuito de verificar que as publicações do perfil divulgam conhecimento científico relacionados às inovações do concreto, bem como, verificar o engajamento nas publicações selecionadas.

\subsection{Análise dos dados retirados da plataforma not just analytics}

O Instagram é um serviço de rede social desenvolvido no ano de 2010 que permite o compartilhamento de vídeos e fotos, e, além disso, é factível utilizar até 2200 caracteres nos textos que acompanham as postagens. É possível constatar que o seu diferencial, em comparação com as demais mídias sociais, consiste em sua natureza visual, enquanto as demais são mais focadas em textos. Os usuários podem acessar a plataforma por intermédio de uma interface web ou aplicativo, nos quais eles possuem diversas opções de filtros a fim de editarem seus respectivos conteúdos. No que se refere às suas funcionalidades, podem-se destacar as seguintes: delimitar os conteúdos com hashtags pesquisáveis, histórias que ficam disponíveis para os demais usuários por 24 horas, possibilidade de mesclar várias imagens ou vídeos em um único post e mensagens privadas (Carpenter \& et al., 2020). Na presente pesquisa optou-se por analisar o Instagram em detrimento do Facebook, uma vez que aquele apresentava maior número de seguidores e interações.

O perfil do projeto Construção + no Instagram possui um total de 876 seguidores com 323 publicações até a data de desenvolvimento da presente pesquisa. Em sua biografia dentro da plataforma ele é apresentado como um projeto de extensão da UFVJM campus Mucuri - Teófilo Otoni e expõe a seguinte frase: “Construindo o conhecimento através da qualificação dos profissionais". Por último, é exibido um link para os interessados terem acesso aos demais canais do projeto. Em seguida, apresenta-se a Figura 1 com os dados obtidos a partir da análise do Not Just Analytics para esse perfil. 
Figura 1 - Informações iniciais e taxa de engajamento do perfil Construção +.

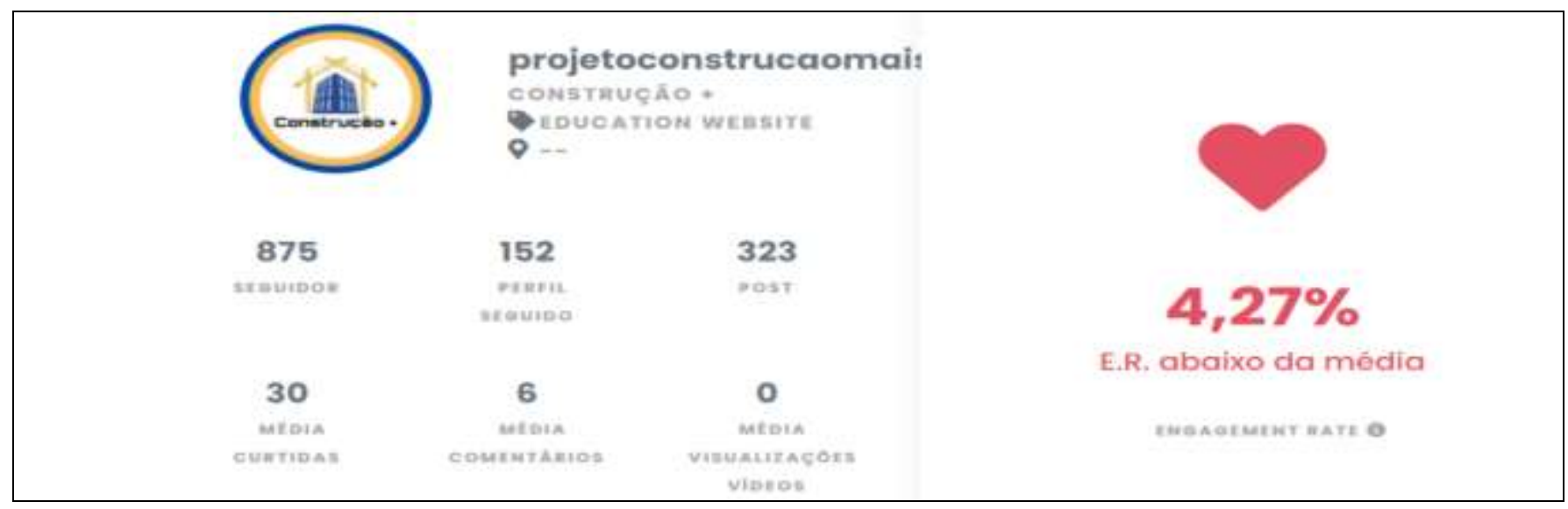

Fonte: Imagem obtida a partir do programa Not Just Analytics (2021)

Observa-se que o perfil possui uma média de 30 comentários por publicação e uma média de 6 curtidas, números ainda reduzidos perante o padrão da plataforma. Também é possível verificar a engagement rate, ou taxa de engajamento em português, que nesse caso é de 4,27\% e está abaixo da média. A taxa de engajamento por meio do programa Not Just Analytics é calculada da seguinte forma: é efetuada uma média de curtidas e comentários dos últimos 12 posts, excluindo a postagem mais recente, e esse valor é dividido pelo número total de seguidores. O programa apresenta diferentes faixas nesse quesito com intuito de demonstrar os valores esperados da taxa de engajamento conforme o número de seguidores, isto é, o perfil do projeto entra na faixa daqueles com um número de seguidores menor do que mil e, para esse grupo, é esperada uma taxa de engajamento de $8 \%$. Ainda com base no programa supracitado, identificou-se que a frequência dos posts é de 4,17 dias.

A seguir, conforme a Figura 2, é apresentada uma nuvem de palavras das hashtags mais utilizadas pelo projeto Construção +.

Figura 2 - Nuvem de palavras das hashtags mais utilizadas.

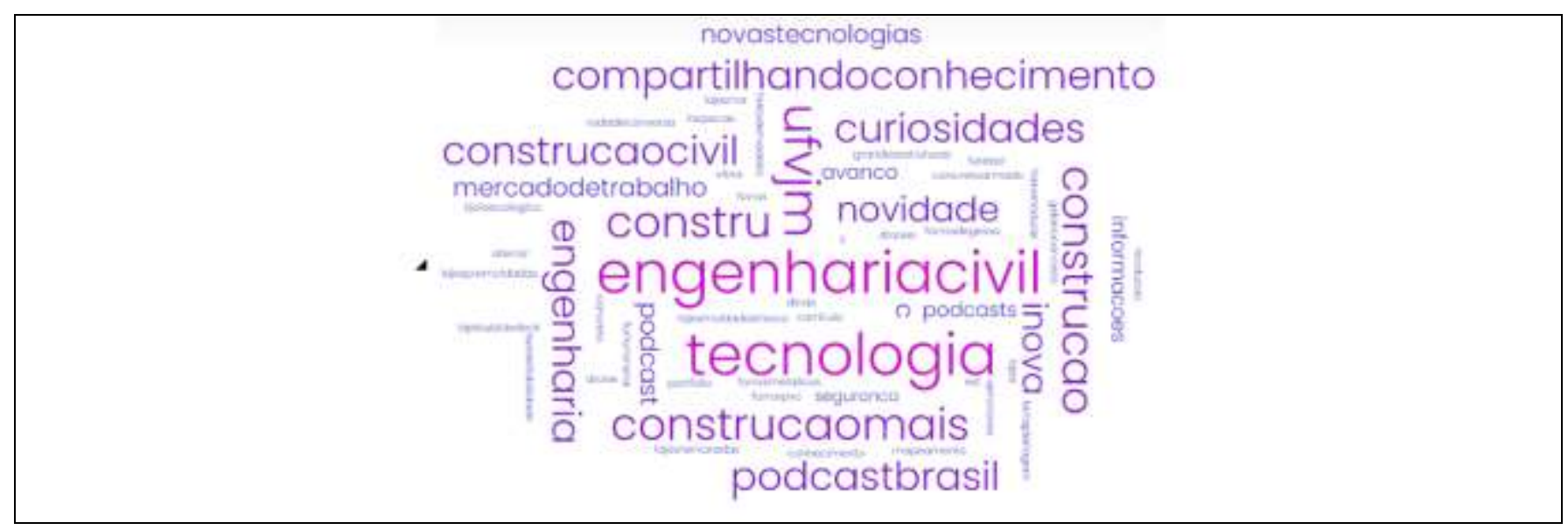

Fonte: Imagem obtida a partir do programa Not Just Analytics (2021).

A nuvem de palavras é uma análise responsável por retratar graficamente as palavras segundo suas frequências. Nesse sentido, as palavras com tamanhos maiores são as que se destacam no perfil do projeto, assim, constata-se que as hashtags mais utilizadas nas publicações são: engenhariacivil (11 vezes), tecnologia (11 vezes), ufvjm (9 vezes), constru (8 vezes),

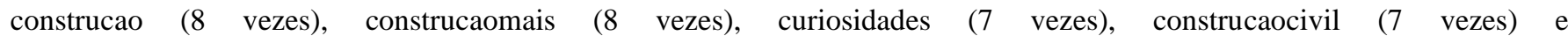
compartilhandoconhecimento (7 vezes). 
De acordo com Ye e et al. (2018) hashtags são extremamente importantes visto que possuem alta capacidade de interconexão e pesquisa, ao contrário de palavras ou frases normais, também se apresentam como um modo eficiente de ampliar a visibilidade dos conteúdos e, consequentemente, garantem que esse conteúdo alcance uma grande quantidade de usuários. O trabalho dos autores também verificou uma relação positiva entre a quantidade de hashtags utilizadas e o número de curtidas e seguidores, além do mais, recomenda-se o uso de palavras simples e autoexplicativas para compor a hashtag, assim como, se ater a grafia correta uma vez que é relevante para a entrega da mensagem. Alguns aspectos que devem ser evitados, conforme os autores, são os seguintes: empregar abreviações desconhecidas ou confusas, que podem culminar em uma falha de reconhecimento, como também, usar palavras enigmáticas ou hashtags não relacionadas à temática que poderão acarretar a criação de sentimentos negativos por parte dos usuários.

\subsection{Análise crítica dos posts}

A partir do Instagram do projeto Construção + foram selecionados alguns posts para serem analisados com intuito de verificar a divulgação do conhecimento científico atrelado às inovações do concreto, bem como, o engajamento com as postagens. Dentre os 4 posts selecionados e submetidos a avaliação, o primeiro aborda o concreto translúcido, conforme Figura 3.

É possível observar que essa publicação, veiculada em 15 de abril de 2021, obteve um total de 34 curtidas, sendo o maior número em relação aos posts analisados, mas nenhum comentário. Esse post apresenta o concreto translúcido como uma inovação da construção civil já que permite a passagem de luz. Ademais, é possível verificar as vantagens e alguns exemplos de locais que podem receber esse material, uma vez que seu uso ainda é bem restrito.

Além da imagem inicial, o post é composto por um vídeo no qual é apresentado de forma lúdica o diferencial desse material que permite visualizar a silhueta de uma mão através do concreto e outras cinco imagens que apresentam a composição do mesmo, seu potencial sustentável e exemplos do seu uso. Nota-se que a linguagem utilizada no resumo do post é clara e de fácil compreensão e no final da mensagem é apresentado o link do site do projeto no qual os usuários encontrarão informações mais detalhadas. Porém, vale salientar que não é um link direto para a matéria do concreto translúcido.

Figura 3 - Imagem do post concreto translúcido.

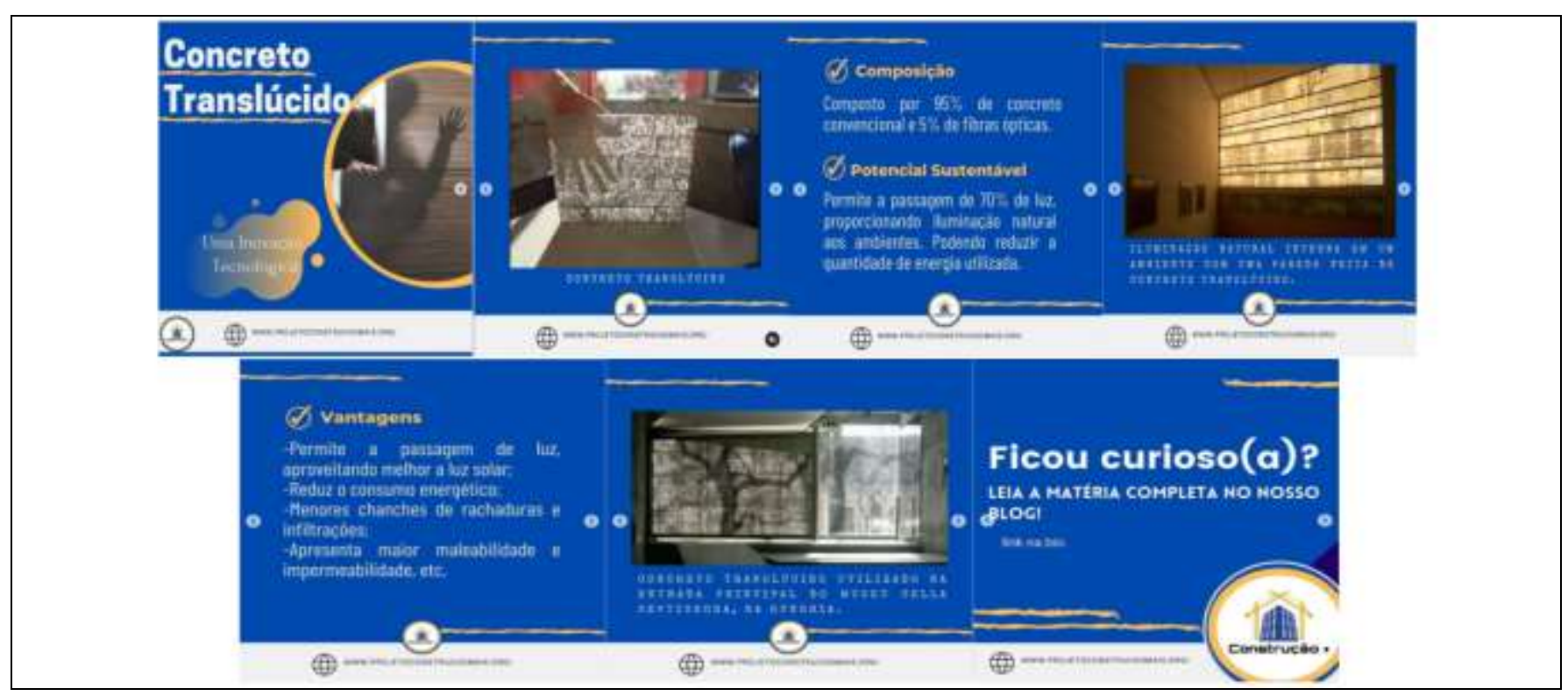

Fonte: adaptado pelos autores a partir do post do Instagram do projeto Construção + (2021) 
O segundo post selecionado, conforme a Figura 4, aborda o bioconcreto e foi publicado em 3 de novembro de 2020, obtendo um total de 34 curtidas e 6 comentários. Desses 6 comentários, somente 3 eram de fato de outros usuários que demonstraram gostar do assunto, os outros três comentários correspondem às respostas do Construção + a esses usuários.

Figura 4 - Imagem do post bioconcreto.

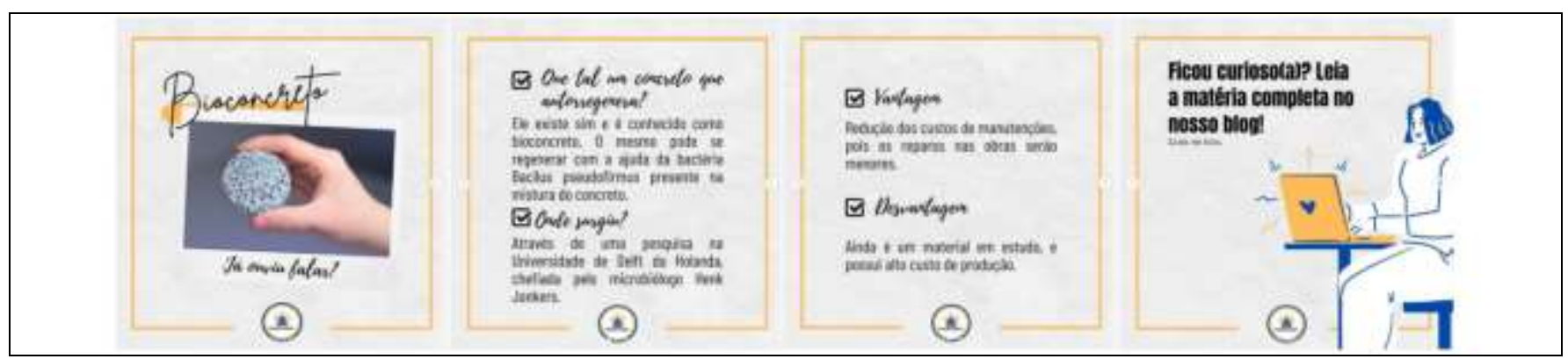

Fonte: adaptado pelos autores a partir do post do Instagram do projeto Construção + (2020).

O post se propõe a explicitar a origem desse tipo de concreto e como o mesmo inovou na construção civil por utilizar bactérias em sua mistura com o propósito de que elas atuem na regeneração da estrutura e, por fim, é salientado que o alto custo de produção ainda é um empecilho para a disseminação dessa tecnologia. Além da imagem inicial, o post apresenta mais três imagens que sintetizam informações do resumo em poucas palavras. Do mesmo modo que o post anterior, o texto é de fácil compreensão e ao final o leitor é convidado a acessar o site para obter mais informações acerca do assunto.

O terceiro post selecionado aborda o concreto leve e foi publicado em 2 de junho de 2020, alcançando um total de 30 curtidas e nenhum comentário, conforme Figura 5. O intuito da publicação é apresentar o concreto leve como uma possibilidade de sanar algumas restrições impostas pelo concreto convencional, nesse caso específico, está relacionado à diminuição do peso do material.

Figura 5 - Imagem do post concreto leve.

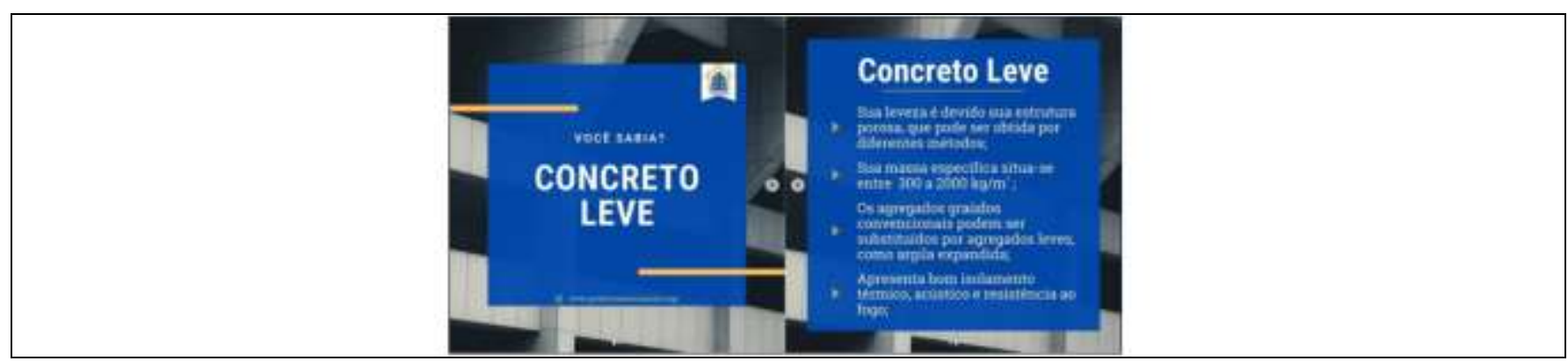

Fonte: adaptado pelos autores a partir do post do Instagram do projeto Construção + (2020).

O resumo do post traz informações sobre a composição do material, a saber, a substituição de agregados graúdos por agregados leves e o acréscimo de espuma na mistura, que acarreta em uma estrutura porosa e, consequentemente, mais leve. Outra informação encontrada no resumo está relacionada à diminuição da resistência à compressão, que é justificada pela redução da massa específica e, por fim, o usuário é convidado a visitar o blog do projeto a fim de obter mais detalhes sobre essa temática, além de outros assuntos. Além da imagem inicial, a publicação é composta por outra imagem que apresenta resumidamente algumas características do concreto leve, tais como: a estrutura porosa pode ser obtida por métodos distintos; a massa específica encontra-se entre 300 a $2000 \mathrm{~kg} / \mathrm{m}^{3}$; a possibilidade de utilizar a argila expandida como agregado leve e, 
finalmente, algumas vantagens como bom isolamento térmico, acústico e resistência ao fogo.

No que tange à temática do concreto colorido, observou-se um total de 3 posts. Dentre esses três, a publicação mais antiga tinha o intuito de apresentar o tema como assunto a ser discutido ao longo da semana, e, à vista disso, não apresentou um resumo sobre o conteúdo. O post da Figura 6 foi selecionado por exibir um pequeno resumo e tratar de forma mais abrangente sobre o concreto colorido. Apesar da matéria completa sobre essa publicação no blog não advir de artigos científicos, percebeu-se outra matéria acerca da temática no blog que continha fontes científicas. Dito isso, a publicação em tela foi postada em 10 de setembro de 2020 e obteve 21 curtidas e nenhum comentário.

Figura 6 - Imagem do post concreto colorido.

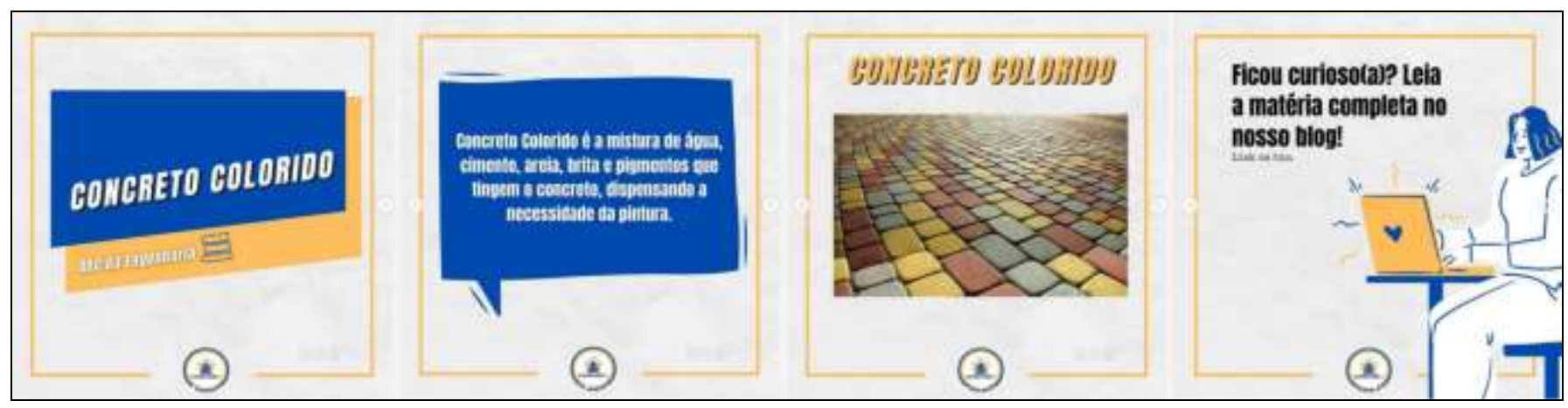

Fonte: adaptado pelos autores a partir do post do Instagram do projeto Construção + (2020).

Já de início, o concreto colorido é apontado como uma tendência que utiliza os mesmos moldes do concreto convencional, no entanto, o seu diferencial está na adição de pigmentos que dão cor a esse concreto, dispensando a necessidade de pintura. Além do mais, a publicação cita que o mesmo pode ser utilizado tanto com finalidade estrutural quanto como decorativa e ainda, traz alguns exemplos de uso comum como: pisos, fachadas, vigas, pilares, lajes ou peças artísticas. No final do resumo há uma recomendação de buscar uma empresa especializada nessa tecnologia devido à dificuldade de identificar a proporção ideal de pigmento e água e, assim como nos posts anteriores, os leitores são convidados a acessar o blog para conhecerem outras vantagens e demais detalhes sobre essa tendência. Além da imagem inicial, o post é composto por mais três imagens, sendo que a primeira expõe resumidamente a composição do concreto colorido e a segunda é uma exemplificação do seu uso em um calçamento, com blocos intertravados.

Em termos mais gerais, verificou-se que o perfil do projeto Construção + no Instagram é recente, já que sua primeira publicação é de 2019, o que pode explicar a sua baixa frequência de curtidas e, principalmente, de comentários. Nesse contexto, Recuero (2014), que faz uma análise dessas ações no Facebook discorre que o botão "curtir" pode ser entendido como uma forma de tomar parte na conversação sem se expor demasiadamente e também uma maneira de legitimar e apoiar o conteúdo de outro perfil na mídia social ou ainda denotar agradecimento pela informação quando ela é interessante e relevante. Já o botão "comentar" traz uma efetiva contribuição para a conversação, requerendo maior empenho por parte dos usuários na elaboração de uma resposta e ocorre quando esses indivíduos possuem algo a dizer sobre a temática em discussão. Por outro lado, comentar envolve mais riscos para a face e para a reputação dado que o usuário se expõe mais nesse tipo de interação. Além do mais, os comentários feitos em uma determinada mídia social podem facilmente ser descontextualizados ao serem compartilhados em outros canais, isso faz com que os usuários percebam um risco mais elevado de exposição, situação essa na qual muitos não estão dispostos a encarar e, consequentemente, acabam optando por somente curtir as publicações.

No que diz respeito ao marketing de conteúdo, é possível verificar na pesquisa de Halevi e O’Hanlon (2016), os quais utilizaram o marketing de conteúdo como uma ferramenta para divulgar os serviços de uma biblioteca acadêmica, bem como, 
conteúdos científicos, eles lançaram mão de regras simples que permitiram expandir e aprimorar o alcance dessa biblioteca online. As sugestões encontradas com o intuito de criar atividades de engajamento e conteúdo de consequência são as seguintes: publicar informações similares em todos os seus canais a fim de reforçar a mensagem; produzir citações, relatórios e fotos dos eventos realizados com a finalidade de alimentar as mídias sociais, posteriormente, com postagens curtas; publicações em diferentes plataformas devem estar vinculadas, isto é, indicando umas para as outras por intermédio de links, visto que essa estratégia possibilita mensagens consistentes, assim como, maior alcance e inclusão de indivíduos que utilizam diferentes plataformas; identificar grupos interessantes na instituição e realizar entrevistas com estes ou, mesmo, evidenciar suas pesquisas de modo a construir conteúdos que irão alimentar postagens nos canais de mídia social.

Destarte, o projeto Construção + pode utilizar dessas etapas com o propósito de ganhar maior engajamento e, consequentemente, maior visibilidade para divulgar conhecimento científico atinente à construção civil.

\section{Considerações Finais}

Este estudo teve como objetivo demonstrar que a divulgação científica relacionada às inovações do concreto pode ser desenvolvida por meio do marketing de conteúdo. Sendo assim, o estudo apresentou algumas publicações, presentes no Instagram do projeto Construção + que retratam temáticas envolvendo o concreto, bem como, dados atinentes ao engajamento da página como um todo retirados do programa Not Just Analytics.

O problema de pesquisa se concentrou em esclarecer como está caracterizada a utilização do marketing de conteúdo na plataforma Instagram pelo projeto Construção + na disseminação de temas inovadores acerca do concreto a partir de uma análise crítica e de engajamento.

Constata-se que o projeto utiliza, claramente, o marketing de conteúdo como uma ferramenta para criar relacionamentos duradouros e levar conhecimento científico, mais especificamente relacionado à construção civil, até seus usuários com uma linguagem clara e de fácil compreensão. Nessa conjectura, o projeto Construção + exibe um aspecto assertivo na questão de utilizar diferentes canais a fim de propagar seus conteúdos, assim como, o uso de diferentes formatos como textos no próprio blog, imagens e vídeos nas redes sociais e áudios por meio de podcast, fazendo com que suas mensagens cheguem a diferentes grupos.

No que diz respeito à análise crítica e de engajamento, conclui-se que em decorrência da sua recente criação ou, talvez, por ser uma página focada em divulgar ciência e demonstrar aspectos informacionais, o número de comentários e curtidas referentes às publicações ainda é reduzido. Uma vez que, com base na literatura, conteúdos com cunho emocional possuem maior capacidade de gerar engajamento. Outros pontos que merecem destaque, se referem aos dados obtidos com base no programa Not Just Analytics, a saber, a taxa de engajamento do perfil ficou na ordem de 4,27 \%, estando abaixo da média ideal, que seria de 8\%; a média de curtidas por publicação foi igual a 30 e a média de comentários igual a 6; a frequência dos posts foi de 4,17 dias; e, por fim, as hashtags mais utilizadas nas publicações são: engenharia civil, tecnologia, ufvjm, constru, construção, construção mais, curiosidades, construção civil e compartilhando conhecimento.

Percebe-se que o marketing de conteúdo se caracteriza como uma ferramenta promissora e estratégica de produção de conteúdo de interesse para um público em específico, com capacidade de atender os processos de consumo e atrair tal público de modo natural e espontâneo. À vista disso, ressalta-se que as universidades, faculdades e instituições afins podem e devem recorrer às possibilidades e vantagens proporcionadas pelos recursos digitais vinculados ao marketing de conteúdo, compartilhando e difundindo conhecimento científico de múltiplas maneiras à comunidade como um todo. 


\section{Dessa forma, destacam-se como sugestões para trabalhos futuros:}

- A importância da publicação e disseminação de conteúdos científicos informacionais e de utilidade;

- Promoção e popularização da ciência e tecnologia com a utilização do marketing de conteúdo, assim como um maior envolvimento do público interessado com o assunto;

- Marketing de conteúdo aplicado na construção civil e em outros contextos de inovação e aplicação do concreto portland;

- Outras estratégias de marketing para divulgação da ciência, tecnologia e inovação da construção civil.

Conclui-se também que a fim de se promoverem maiores e melhores interações com o público alvo atingido pelo Construção +, sugestões podem ser idealizadas e desenvolvidas para tais fins como, por exemplo, a produção de citações, relatórios e registros fotográficos de eventos com o objetivo de alimentar suas mídias sociais; a identificação de grupos e entidades interessantes na instituição e a realização de entrevistas com estes ou, até mesmo, evidenciar suas pesquisas de modo a construir conteúdos que trarão fomentos às postagens nos canais de mídia social.

\section{Referências}

Aguiar, C. A. (2006). Concreto cimento Portland branco estrutural: análise da adição de pigmentos quanto à resistência à compressão (Dissertação de mestrado). Universidade Federal do Rio Grande do Sul.

Aïtcin, P.-C. (2016). Portland cement. In Aïtcin, P.-C., \& Flatt, R. J (Orgs.), Science and Technology of Concrete Admixtures, Woodhead Publishing.

Alencar, V. A. (2018). Análise de estratégias de marketing de conteúdo viral na divulgação científica de astronomia (Trabalho de Conclusão de Curso). Universidade Federal do Ceará, Fortaleza, CE, Brasil.

Almeida, R. B. F. D. (2019). Proposição de estratégias de marketing digital para pesquisadores utilizarem as redes sociais como forma de divulgação científica (Dissertação de mestrado). Instituto de Química e Biotecnologia, Universidade Federal de Alagoas.

Almeida, E. D. S. (2020). Resíduos cerâmicos da indústria do pólo cerâmico de Iranduba e Manacapuru como material pozolânico e mitigador de reação alcális-agregado (Dissertação de mestrado). Universidade Federal do Amazonas, Manaus, AM, Brasil.

Angelin, A. F. (2014). Concreto leve estrutural - Desempenhos, físicos, térmicos, mecânicos e microestruturais (Dissertação de mestrado). Faculdade de Tecnologia da Universidade Estadual de Campinas.

Barbosa, J. M. (2017). A influência da moagem na atividade pozolânica do resíduo de granito (Dissertação de mestrado). Universidade Federal de Ouro Preto.

Barros, L. A. (2006). Aspectos epistemológicos e perspectivas científicas da terminologia. Ciência e Cultura, 58 (2), $22-26$.

Calado, C. F. de. A., Camões, A., Jalali, S., \& Júnior, B. B. (2015). Concreto Auto-Adensável (CAA), Mais do que Alternativa Ao concreto Convencional (CC). Editora da Universidade de Pernambuco.

Carpenter, J. P., Morrison, S. A., Craft, M., \& Lee, M. (2020). How and why are educators using Instagram? Teaching and teacher education, $96,103149$.

Content Marketing Institute (n.d.). What is Content Marketing? https://contentmarketinginstitute.com/what-is-content-marketing/

Construção + (2020). ABC Da Engenharia: Concreto Colorido. https://www.instagram.com/p/CE-X7RLgfQY/

Construção + (2021). Bioconcreto. https://www.instagram.com/p/CHJKCJdAEPc/

Construção + (2020). Concreto Leve. https://www.instagram.com/p/CA8rFDdj_Y4/

Construção + (2021). Concreto Translúcido._https://www.instagram.com/p/CNs2HYQgUQF/

Construção + (n.d). O projeto. https://www.projetoconstrucaomais.org/

Costa, D. D., \& Nascimento, T. S. (2011). A gestão do desenvolvimento de produtos na indústria de materiais de construção. Revista de Administração Contemporânea, 15 (1), p. 1-24.

Costa, L. F., Andrade, R. L. V., Silva, A. C. P., Duarte, E. N., \& Souza, A. C. P. (2016). O uso de mídias sociais por revistas científicas da área da Ciência da Informação para ações de marketing digital. Revista ACB: Biblioteconomia em Santa Catarina, 21(2), 338-358.

Couto, J. A. S., Carminatti, R. L., Nunes, R. R. A., \& Moura, R. C. A. (2013). O concreto como material de construção. Cadernos de Graduação - Ciências Exatas e Tecnológicas, 1 (3), 49-58.

Ferreira, M. L., \& Chiaretto, S. (2016). Marketing de conteúdo em ambiente digital: uma estratégia de Branding na perspectiva evolutiva do Marketing. Revista Cientifica de Comunicação Social do Centro Universitário de Belo Horizonte (UniBH), 9 (1), 63-80. 
Fonseca, J. J. (2002). Metodologia da pesquisa científica. UEC.

Garcia, E., Cabral, M., Quarcioni, V. Â., \& Chotoli, F. F. (2014). Resíduo de Cerâmica Vermelha (RCV): Uma Alternativa como Material Pozolânico. Cerâmica Industrial, 19 (4), 31-38.

Giacomelli, A. \& Mantovanni, C. (2014). Concreto Translúcido: A nova tendência estética na construção. $12^{\circ}$ Encontro Científico Cultural Interinstitucional.

Gil, A. C. (2017). Como elaborar projetos de pesquisa. Atlas.

Grainge, P. (2017). Ancillary academia: video shorts and the production of university paratexts. Critical Studies in Media Communication, 34(2), 184-192.

Halevi, G. \& O'Hanlon, R. (2016). Creating content marketing for libraries. Journal of the Medical Library Association: JMLA, $104(4), 342$.

Halvorson, K. (2012). Estratégia de conteúdo para web. Alta Books.

Helene, P. \& Andrade, T. (2010). Concreto de Cimento Portland. In: Isaia, G. C. (Coord.). Materiais de construção civil e princípios de ciência e engenharia de materiais. São Paulo: IBRACON.

Ivanissevich, A. (2009). A missão de divulgar ciência no Brasil. Ciência e Cultura, 61(1), 4-5.

Jurno, A. C. (2017). A fórmula da ciência no Facebook: conteúdo+ linguagem+ usuários+ algoritmos= alcance e visibilidade?. In V. Fagundes, \& M. G. Silva (Orgs.). Divulgação científica: novos horizontes (pp. 57-76). Mazza Edições.

Kotler, P., Kartajaya, H. \& Setiwan, I. (2017). Marketing 4.0: do tradicional ao digital: Sextante.

Mariano, C. R. (2019). Marketing de conteúdo e engajamento na comunicação da ciência veiculada pela Clínica Pleni (Trabalho de Conclusão de Curso). Universidade Federal de Uberlândia, Uberlândia, MG, Brasil.

Mehta, P. K. \& Monteiro, P. J. M. (2014). Concreto Microestrutura, Propriedade e Materiais: IBRACON.

Moberg, A., Finnveden, G., Johansson, J., \& Lind, P. (2005). Life cycle assessment of energy from solid waste—part 2: landfilling compared to other treatment methods. Journal of Cleaner Production, 13(3), 231-240.

Not Just Analytics (2021). Not Just Analytics. https://www.notjustanalytics.com/

Pharr, J. M. (2019). Best practices in digital content marketing for building university brands. Association of Marketing Theory and Practice Proceedings 2019. 8 .

Pratt, P. L. \& Jennings, H. M. (1981). The Microchemistry and Microstructure of Portland Cement. Annual Review of Materials Science, 11(1), 123-149.

Ramalho, D. A. F. (2016). Marketing de Conteúdo: Análise das páginas Sagres e Super Bock no Facebook (Dissertação de mestrado). Universidade Nova de Lisboa, Lisboa, Portugal.

Recuero, R. (2014). Curtir, compartilhar, comentar: trabalho de face, conversação e redes sociais no Facebook. Verso e reverso, 28(68), 117-127.

Reis, L. V. (2017). Biotecnologia microbiana da construção: potencial de biomineralização de bactérias ureolíticas de solo de cerrado e de rejeitos de construção civil (Dissertação de mestrado). Universidade Federal de Goiás.

Rez, R. (2016). Marketing de conteúdo: a moeda do século XXI. DVS Editora.

Rodrigues, D. C. (2017). Inovações tecnológicas do concreto: Uma análise do cenário atual do concreto na construção civil e suas expectativas (Especialização). Universidade Regional do Carirí, Juazeiro do Norte, CE, Brasil.

Sattler, M. A. (2002). Edificações e comunidades sustentáveis: atividades em desenvolvimento no NORIE/UFRGS. Anais do Seminário Ibero-Americano da Rede CYTED XIV.C, 4.

Shi, C., Jimenez F. A., \& Palomo, A. (2011). New cements for the 21 st century: the pursuit of an alternative to Portland cement. Cement and Concrete Research, 41(7), 750-763.

Sousa, G. M., Rocha, C. A. M.. \& Gomes, A. J. L. (2020). Variation of compressive strength in colored concrete traces in the city of Teófilo Otoni in the State of Minas Gerais. International Journal of Geoscience, Engineering and Technology, 2(1), 23-31.

Sousa, G. M., Oliveira, K. R. \& Gomes, A. J. L. (2020). Compressive Strength of Colored Concrete with iron oxide in the city of Teófilo Otoni in Minas Gerais. International Journal of Geoscience, Engineering and Technology, 1(1), 69-77.

Silva, F. P. C., Passarini, V. C., \& Santos, F. C. S. (2017). Bioconcreto: a tecnologia para a construção sustentável. INOVAE, 5 (2), 41-58.

Tan, H., Li, M., He, X., Su, Y., Zhang, J., Pan, H., Yang, J., \& Wang, Y. (2019). Preparation for micro-lithium slag via wet grinding and its application as accelerator in Portland cement. Journal of Cleaner Production, 250, 119528.

Targino, M. D. G. (2007). Divulgação científica e discurso. Comunicação \& Inovação, 8 (15), 19-28.

Valença, J. V. \& Priszkulnik, S. (2017). Concreto colorido: Influência da adição de pigmentos e suas aplicações. XIII Jornada de Iniciação Científica e VII Mostra de Iniciação Tecnológica. Universidade Presbiteriana Mackenzie. 13. 
Research, Society and Development, v. 10, n. 10, e31101018538, 2021

(CC BY 4.0) | ISSN 2525-3409 | DOI: http://dx.doi.org/10.33448/rsd-v10i10.18538

Vieira, V. A. (2002). As tipologias, variações e características da pesquisa de marketing. Revista FAE, 5 (1), p. $61-70$.

Vinerean, S. (2017). Content marketing strategy. Definition, objectives and tactics. Expert Journal of Marketing, 5, 92-98.

Wall, A., \& Spinuzzi, C. (2018). The art of selling-without-selling: Understanding the genre ecologies of content marketing. Technical Communication Quarterly, 27(2), 137-160.

Yaghtin, S., Safarzadeh, H., \& Zand, M. K. (2020). Planning a goal-oriented B2B content marketing strategy. Marketing Intelligence \& Planning, 38 (7), p. 1007-1020.

Ye, Z., Hashim, N. H., Baghirov, F., \& Murphy, J. (2018). Gender differences in Instagram hashtag use. Journal of Hospitality Marketing \& Management, 27(4), 386-404.

Zhu, J., Yang, K., Chen, Y., Fan, G., Zhang, L., Guo, B., Guan, X., \& Zhao, R. (2020). Revealing the substitution preference of zinc in ordinary Portland cement clinker phases: A study from experiments and DFT calculations. Journal of Hazardous Materials, 409, 1-10. 